\title{
Endoscopic ultrasound-guided hepaticogastrostomy combined with novel uncovered metal stent
}
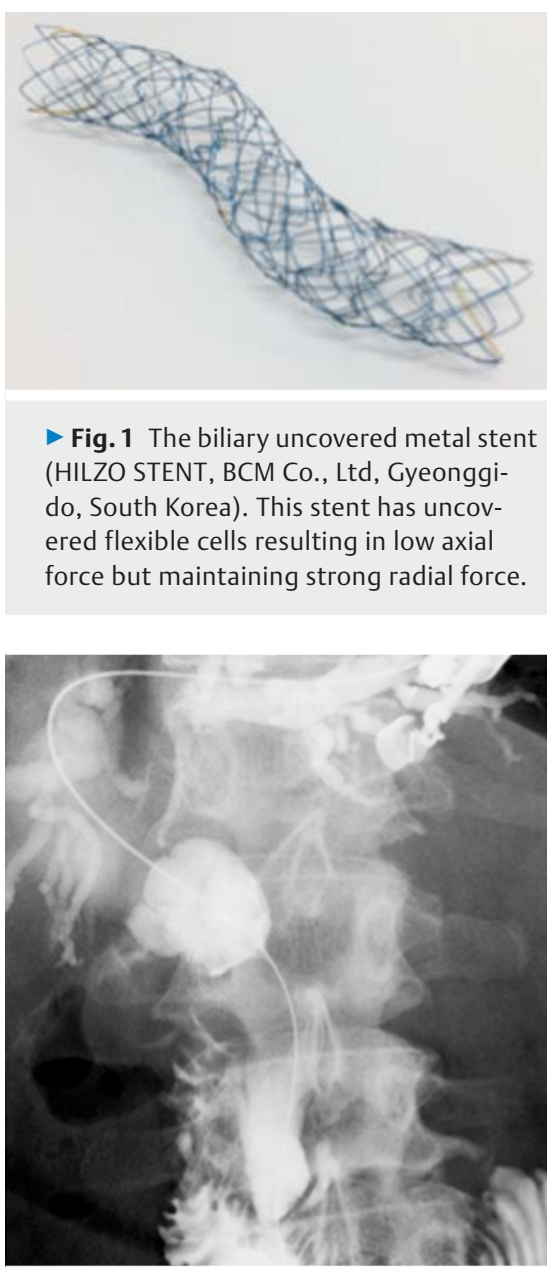

> Fig. 2 Bile duct obstruction was seen in the middle common bile duct with a relatively tortuous bile duct axis.
Endoscopic ultrasound-guided hepaticogastrostomy (EUS-HGS) has been developed as an alternative method for biliary drainage after failed endoscopic retrograde cholangiopancreatography (ERCP) [1]. EUS-HGS may be indicated for patients with advanced disease stages $[2,3]$. However, following recent developments in chemotherapy, such as FOLFIRINOX (folinic acid + fluorouracil+ irinotecan + oxaliplatin) [4], longer survival may be obtained; therefore, longer stent patency is clearly required.

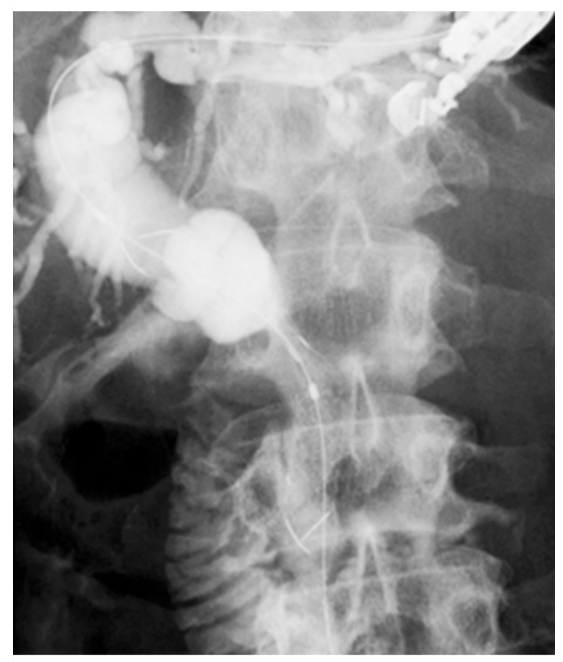

- Fig. 3 Antegrade stent deployment was performed for the novel uncovered metal stent.

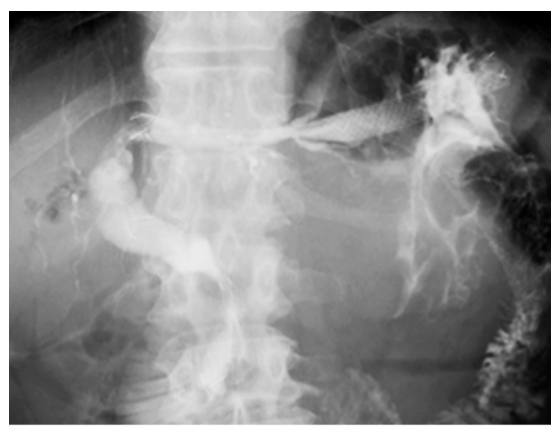

- Fig. 4 Endoscopic ultrasound-guided hepaticogastrostomy was performed using a partially covered metal stent.

Recently, EUS-HGS combined with antegrade stent placement has been reported for this purpose [5]. For this technique, to prevent stent dislocation or misplacement due to stent shortening, a laser-cut-type, uncovered, metal stent may be preferred. However, if the angle of bile duct axis is acute, stent expansion may be insufficient due to low radial force. Recently, a novel, uncovered, metal stent has become available in Japan $(\triangleright$ Fig. 1). This stent has uncovered flex-

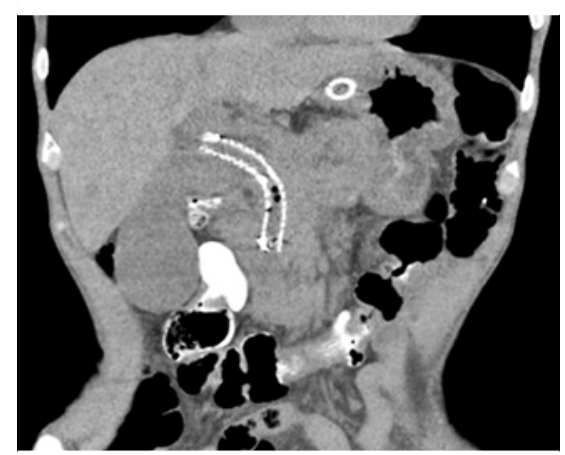

- Fig.5 Full expansion of the flexible metal stent was confirmed on computed tomography.

ible cells but maintains a strong radial force. Stent deployment is therefore possible along the bile duct axis. Herein, we describe the technical tips for EUS-HGS with antegrade stent placement using this novel stent.

A 78-year-old man was admitted to our hospital with obstructive jaundice due to gastric cancer. The patient had undergone gastrojejunostomy for gastric outlet obstruction 6 months earlier. Therefore, EUS-guided access was attempted as a drainage method.

First, the intrahepatic bile duct was punctured using a 19-gauge fine-needle aspiration needle, and the guidewire was placed. Then, an ERCP catheter was inserted into the biliary tract, and the contrast medium was injected. On cholangiography, bile duct obstruction was seen in the middle common bile duct with a relatively tortuous axis (\$ Fig. 2 ). Therefore, a flexible uncovered metal stent $(10 \mathrm{~mm} \times 8 \mathrm{~cm})$ was deployed in an antegrade fashion (> Fig.3). Finally, EUS-HGS was performed using a partially covered metal stent ( $\triangleright$ Fig. 4 ).

The following day, full expansion of the flexible metal stent was confirmed on computed tomography ( $\triangleright$ Fig. 5 ).

A flexible stent may be clinically useful, not only for multi-stenting in a through- 


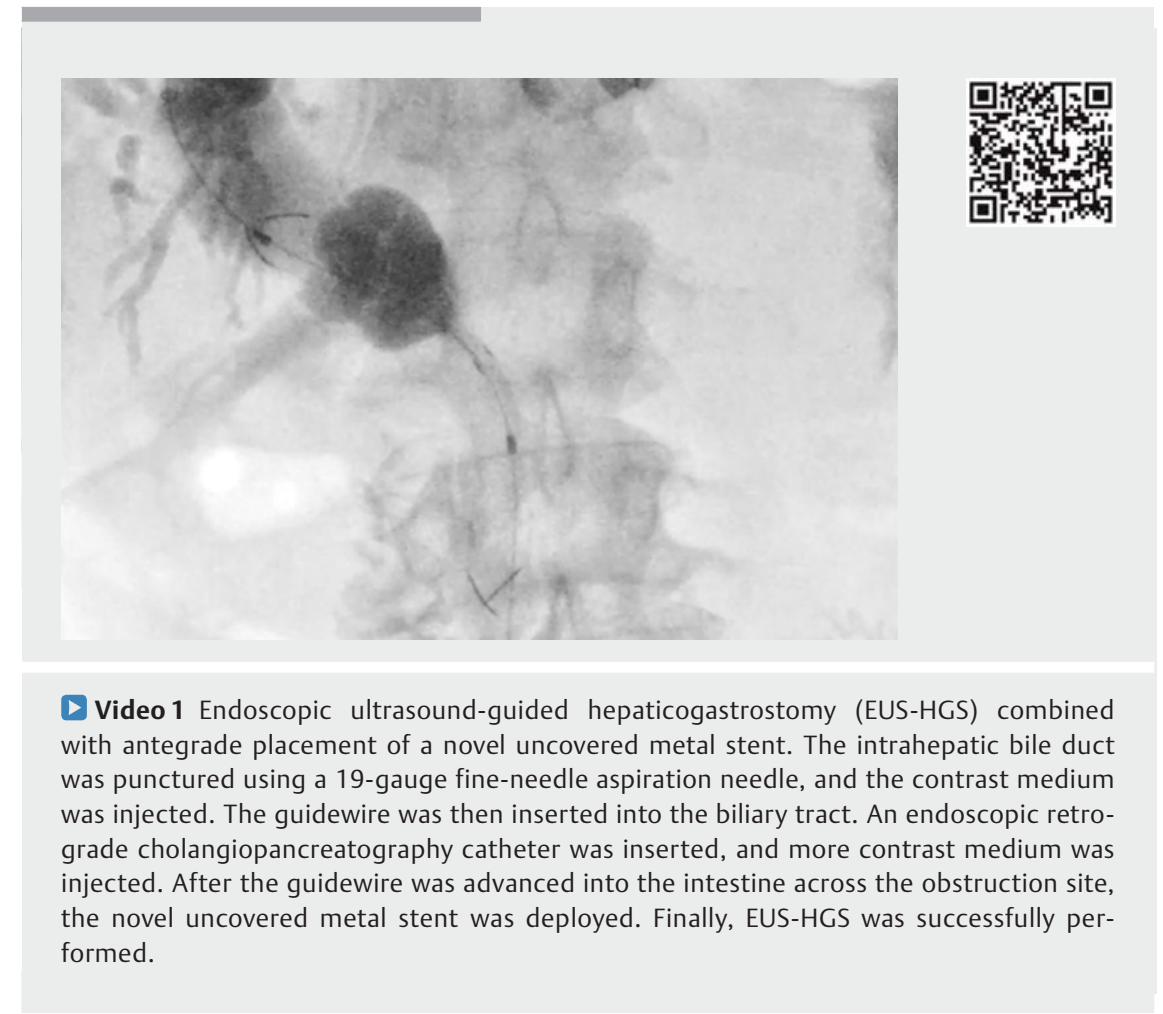

the-stent technique under ERCP guidance, but also in EUS-HGS combined with antegrade stent placement.

Endoscopy_UCTN_Code_TTT_1AS_2AD

Competing interests

None

The authors

Takeshi Ogura, Nobu Nishioka, Akira Miyano, Rieko Kamiyama, Kazuhide Higuchi

2nd Department of Internal Medicine, Osaka

Medical College, Osaka, Japan

\section{Corresponding author}

\section{Takeshi Ogura, MD}

2nd Department of Internal Medicine, Osaka

Medical College, 2-7 Daigakuchou,

Takatsukishi, Osaka 569-8686, Japan

Fax: +81-72-6846532

oguratakeshi0411@yahoo.co.jp

\section{References}

[1] Boulay BR, Lo SK. Endoscopic ultrasoundguided biliary drainage. Gastrointest Endosc Clin N Am 2018; 28: 171 - 185

[2] Baars JE, Kaffes AJ, Saxena P. EUS-guided biliary drainage: a comprehensive review of the literature. Endosc Ultrasound 2018; 7: 4-9
[3] Ogura T, Higuchi K. Technical tips for endoscopic ultrasound-guided hepaticogastrostomy. World J Gastroenterol 2016; 22: 3945-3951

[4] Conroy T, Desseigne F, Ychou M et al. FOLFIRINOX versus gemcitabine for metastatic pancreatic cancer. N Engl J Med 2011; 364: $1817-1825$

[5] Ogura T, Kitano M, Takenaka M et al. Multicenter prospective evaluation study of endoscopic ultrasound-guided hepaticogastrostomy combined with antegrade stenting (with video). Dig Endosc 2018; 30: 252 - 259

\section{Bibliography}

DOI https://doi.org/10.1055/a-0756-7341

Published online: 7.11.2018

Endoscopy 2019; 51: E12-E13

(c) Georg Thieme Verlag KG

Stuttgart · New York

ISSN 0013-726X

\section{ENDOSCOPY E-VIDEOS \\ https://eref.thieme.de/e-videos}

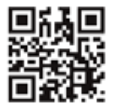

Endoscopy E-Videos is a free access online section, reporting on interesting cases and new

techniques in gastroenterological endoscopy. All papers include a high quality video and all contributions are freely accessible online.

This section has its own submission website at https://mc.manuscriptcentral.com/e-videos 